\title{
Heterogeneity of Adult Rhinitis for Multimorbidity and Age at Onset among Non-Sensitized Rhinitis and Mono-/Poly-Sensitized Rhinitis: A Retrospective Cross-Sectional Study
}

\author{
Jae Won Jeong ${ }^{a}$ Kyu-Hyoung Lim ${ }^{b}$ Woo Hyun Lee ${ }^{c}$ Jun Yeon Won ${ }^{c}$ \\ Jae-Woo Kwon ${ }^{b}$ \\ aDepartment of Internal Medicine, Inje University College of Medicine, Goyang, Republic of Korea; ${ }^{\mathrm{b}}$ Department of \\ Internal Medicine, Kangwon National University School of Medicine, Chuncheon, Republic of Korea; 'Department of \\ Otolaryngology, Kangwon National University School of Medicine, Chuncheon, Republic of Korea
}

\author{
Keywords \\ Rhinitis · Asthma · Conjunctivitis · Eczema · Nonatopic · \\ Sensitization
}

\begin{abstract}
Background: Recent studies have proposed that clinical and immunological differences exist between mono- and polysensitized subjects with allergic diseases, and poly-sensitization was related to multimorbidity of allergic diseases among children and adolescents. Objective: We compared the clinical characteristics and multimorbidity of allergic diseases between adult rhinitis patients mono- and poly-sensitized to common aeroallergens using a retrospective cross-sectional study for tertiary care subjects. Methods: The medical records of 1,615 patients who were clinically diagnosed with rhinitis by an otolaryngologist and evaluated with skin prick tests were reviewed. The severity of the rhinitis symptoms, comorbidities (asthma, conjunctivitis, and eczema), family history of allergic diseases, and the results of skin prick tests were evaluated. Results: There were 392 patients with mono-sensitized rhinitis (mono-sR), 325 with poly-sensitized rhinitis (poly-sR), and 898 with non-sensitized rhinitis (nonsR). Comorbid conjunctivitis and eczema were most com-
\end{abstract}

mon in poly-sR, followed by mono-sR, and least common in non-sR patients. The age at onset of rhinitis was clearly different between adult patients with non-sR and mono-/poly$s R$, but not between patients with mono-sR and poly-sR. However, the age at onset of rhinitis was much younger in non-sR and mono-sR patients with conjunctivitis or eczema than those without such comorbidities. Conclusion: The frequency of comorbid conjunctivitis and eczema in adult rhinitis patients differed by a quantitative trait of immunoglobulin E sensitization. Depending on the multimorbidity of allergic diseases, onset age of rhinitis seems to be different in adult rhinitis patients.

๑) 2020 S. Karger AG, Basel

\section{Introduction}

Allergy-related diseases such as eczema, rhinitis, and asthma are not only common in children but also often coexist in many children [1]. These findings suggest that atopy could be a common link among these diseases,

W.K. and J.Y.W. equally contributed as the corresponding authors. Edited by: A. Haczku, Sacramento, CA.

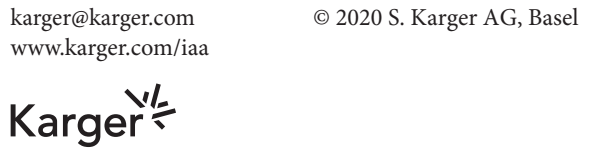


Fig. 1. Distribution of the age at onset according to the quantitative trait of IgE sensitization. IgE, immunoglobulin E; non-sR, non-sensitized rhinitis; mono-sR, monosensitized rhinitis; poly-sR, poly-sensitized rhinitis.

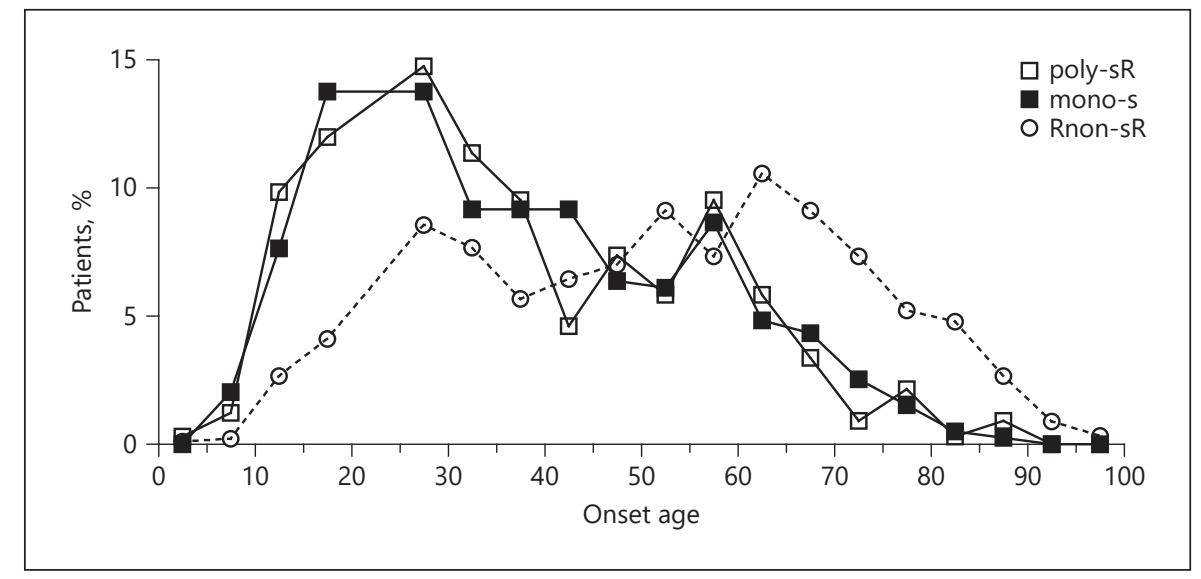

called the atopic march [2]. However, the Mechanisms of the Development of ALLergy (MeDALL) project, consisting of 14 European birth cohorts, reported that immunoglobulin E (IgE) sensitization accounted for only $38 \%$ of the multimorbidity of allergic diseases among children population [3]. Furthermore, the MeDALL study suggested that clinical and immunological differences exist between mono- and poly-sensitized subjects, because of a quantitative trait of IgE sensitization [3], and poly-sensitization was related to multimorbidity and the persistence of allergic diseases over time [4-6]. The differences in clinical characteristics and relationships with multimorbidity according to mono-sensitization, poly-sensitization, and non-IgE-mediated mechanisms have come from a population of children and adolescents [6-8].

Such allergy-related diseases are also common in the adult population [9]. However, the adult population is suspected to have more diverse endotypes other than allergic pathogenesis in their allergic diseases than in their younger counterparts [9]. Actually, asthma beginning after the fourth decade is known to be characterized as nonatopic or intrinsic [10]. For rhinitis, there are much more adult patients with non-sensitized rhinitis (non-sR) [11, 12], which is not only a risk factor for asthma but also showed a stronger association with asthma than allergic rhinitis in a European population [13]. Even the pattern of inflammation in chronic rhinitis seems different between Caucasian and Asian adult patients [14]. Although there have been many studies on rhinitis in adults [15], an evaluation of the differences in rhinitis based on multimorbidity and the quantitative trait of IgE sensitization has not been undertaken in an adult population.

We hypothesized that adult rhinitis might also be heterogenous in clinical characteristics such as onset age of rhinitis, gender difference, and comorbidity, including prevalence of multimorbidity and age when comorbidity occurs according to the quantitative trait of IgE sensitization. So we carried out a cross-sectional analysis of patients who visited a rhinitis clinic and compared the clinical characteristics of adult patients with non-sR and those with rhinitis mono- and poly-sensitized to common aeroallergens.

\section{Methods}

\section{Study Subjects}

The medical records of adult patients with rhinitis who visited the rhinitis clinic, Kangwon National University Hospital, South Korea, from August 2003 to November 2014 for the first time were reviewed. Patients who visited the rhinitis clinic for the first time and diagnosed with rhinitis by an otolaryngologist were evaluated with a structured form of medical records and skin prick tests. Rhinitis was diagnosed by one otolaryngologist based on more than 2 typical symptoms of rhinitis, including watery rhinorrhea, sneezing, nasal obstruction, and itching. The inclusion criteria were rhinitis patients aged $\geq 20$ years and the presence of skin prick test results. The exclusion criteria included any missing data from the structured form of medical records and skin prick tests, and the presence of nasal polyps and sinusitis.

The structured form of medical records for rhinitis patients included history of comorbidities, family history of allergic diseases, type of residence (apartment building, detached house, townhouse, or villa), indoor environment (carpeted, bedding, and pets), and details of rhinitis symptoms such as the onset of rhinitis symptom, the most troublesome symptom (this multiple-choice question included stuffy nose, sneezing, itching, dysosmia, and cough), severity of the symptoms (sneezing, rhinorrhea, stuffy nose, itching, and sensation of posterior nasal drip were rated on a 10-point scale, and their effects on daily life were rated on a 4-point Likert scale), seasonal and diurnal variations, and aggravating factors.

Diagnosis of comorbidity including asthma, sinusitis, eczema, and diabetes mellitus was identified based on the patient 
statements, for which the patients were asked if they had ever suffered from comorbid conditions, including asthma, sinusitis, eczema, and diabetes mellitus, but comorbid conjunctivitis was defined as current itching of the eye. Skin prick tests were performed on the volar aspect of the forearm using a test kit that included 10 common inhalant allergens (Allergopharma Co., Reinbek, Germany), a positive control (histamine; $1 \mathrm{mg} / \mathrm{mL}$ ), and negative diluent controls (Allergopharma) according to the standard protocol by the Global Allergy and Asthma European Network [16]. The 10 common inhalant allergens included $D$. pteronyssinus, D. farinae, a tree pollen mix, a grass pollen mix, ragweed, mugwort, Alternaria, Aspergillus, dog hair, and cat fur. Atopy was defined as the presence of at least one positive response on the skin prick test (wheal diameter of allergen $\div$ wheal diameter of histamine $\geq 1$ ) and a mean wheal diameter $\geq 2 \mathrm{~mm}$ $[17,18]$. Mono-sensitization was defined as a positive response to only one allergen; however, positive responses to both $D$. pteronyssinus and $D$. farinae were regarded as a positive response to 1 allergen because of cross-reactivity in house dust mites (HDM), and poly-sensitization was defined as a positive response to 2 or more allergens.

\section{Statistical Analyses}

The clinical characteristics and demographic data are presented as means and standard deviation (SD) for continuous variables; the relative frequencies of categorical variables were compared using a one-way ANOVA for 3 groups and a Student's $t$ test or a $\chi^{2}$ test for 2 groups. To present the onset age of rhinitis in each type of rhinitis, prevalence of rhinitis is presented with 5-year intervals in Figure 1 All statistical analyses were performed using SPSS software ver. 12.0 for Windows (SPSS Inc., Chicago, IL, USA). Statistical significance was set at $p$ values $<0.05$.

Table 1. Clinical characteristics of the study population

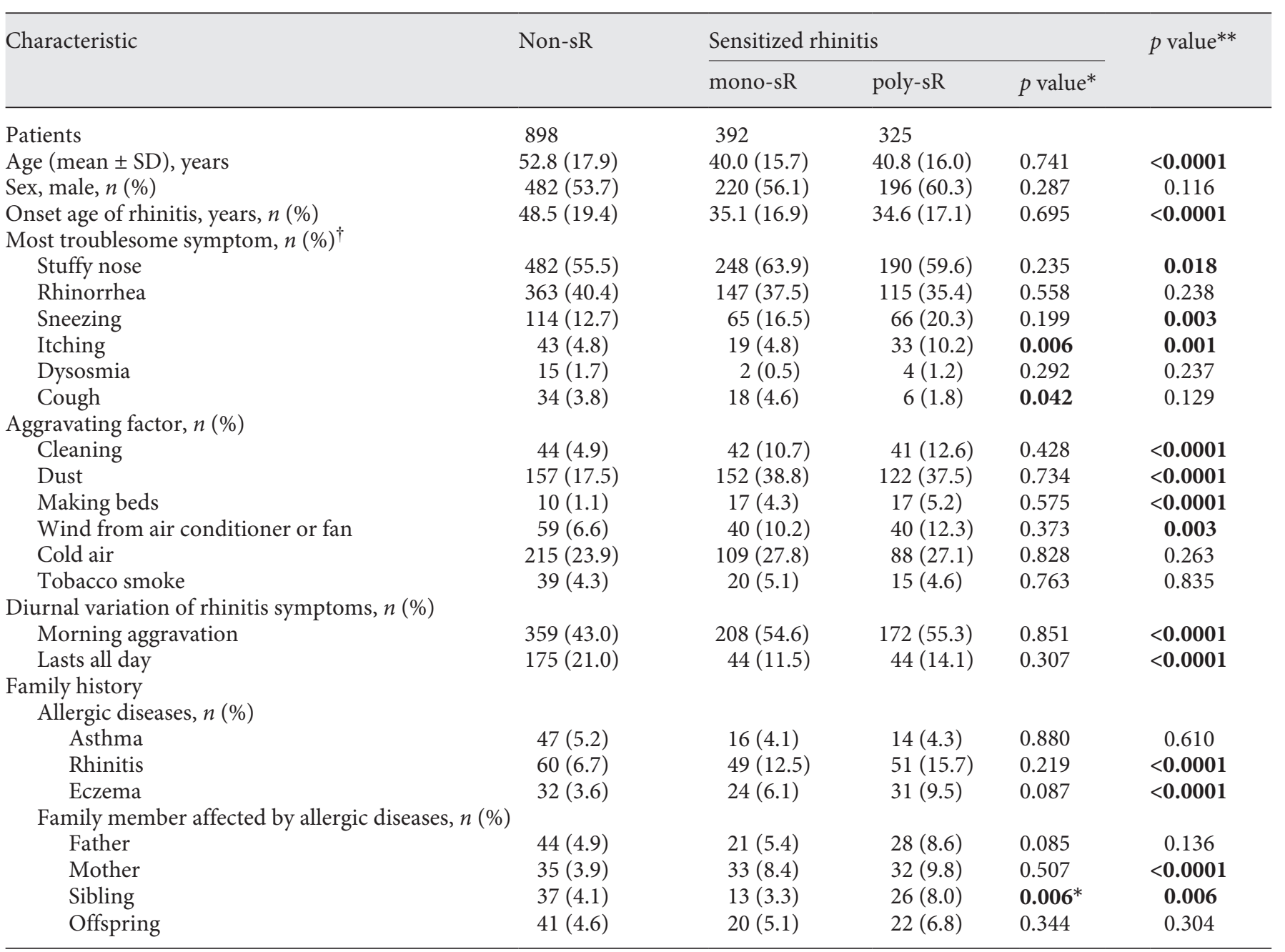

Mono-sR, mono-sensitized rhinitis; poly-sR, poly-sensitized rhinitis; non-sR, non-sensitized rhinitis. Bold typeface indicates $p<0.05$. * Comparison between mono-sR and poly-sR. ${ }^{* *}$ Comparison among non-sR, mono-sR, and poly-sR. ${ }^{\dagger}$ Patients could select multiple answers from the symptoms mentioned. 


\section{Results}

This study included 1,615 patients with rhinitis, 898 patients with non-sR, 392 patients with mono-sensitized rhinitis (mono-sR), and 325 patients with poly-sensitized rhinitis (poly-sR) (Table 1). Patients with non-sR were older and showed late onset of rhinitis symptoms com-

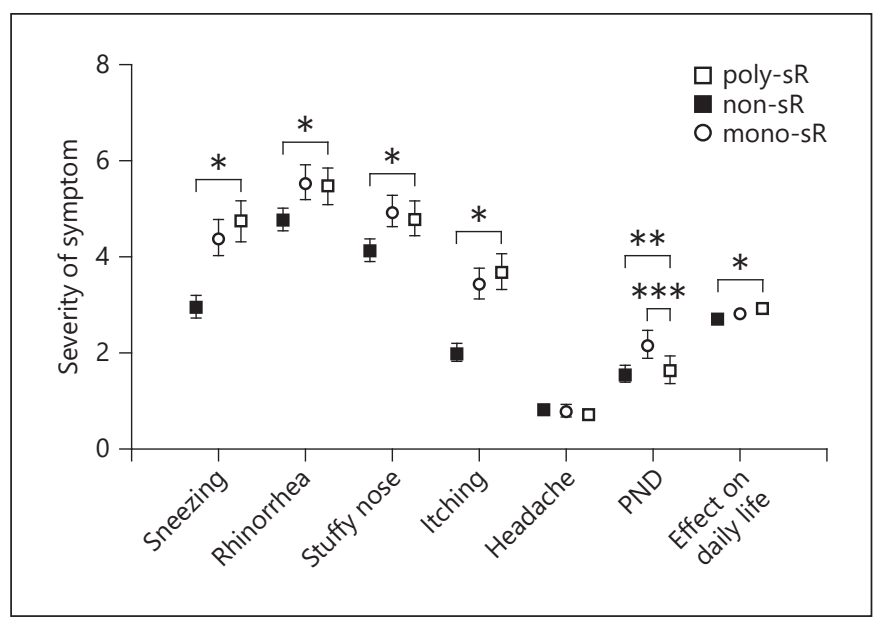

Fig. 2. Severity of each symptom according to non-sR, mono-sR, and poly-sR. All of the presented symptoms were evaluated with a 10-point scale except their effects on daily life, which were rated on a 4-point Likert scale. Data are presented as mean with SE. Non$\mathrm{sR}$, non-sensitized rhinitis; mono-sR, mono-sensitized rhinitis; poly-sR, poly-sensitized rhinitis; PND, postnasal drip; SE, standard error. pared with patients with sensitized rhinitis, but age of patients and onset age of rhinitis did not differ between patients with mono-sR and poly-sR. Diurnal variation in rhinitis symptoms seemed to be more prominent in sensitized rhinitis than in non-sR. Family history of each allergic disease also seemed to show the quantitative trait of IgE sensitization, but not significant between poly-sR and mono-sR. Figure 1 shows the distribution of the onset age of rhinitis among adult patients with non-sR and sensitized rhinitis. Nasal symptoms were more severe in patients with sensitized rhinitis, but there were no differences between patients with mono-sR and poly-sR (Fig. 2).

In terms of comorbidities (Fig. 3), conjunctivitis was most common in patients with poly-sR: $14.3 \%(128 / 898)$ of non-sR patients, $27.3 \%$ (107/392) of mono-sR patients, and $36.9 \%(120 / 325)$ of poly-sR patients $(p<0.0001)$. Eczema occurred in 5.9\% (53/898) of non-sR patients, $8.9 \%$ (35/392) of mono-sR patients, and $12.3 \%(40 / 325)$ of poly-sR patients $(p=0.0001)$. Asthma did not exhibit such a trend: $4.1 \%(37 / 898)$ of patients with non-sR, $7.1 \%$ (28/392) of patients with mono-sR, and $6.2 \%(20 / 325)$ of patients with poly-sR $(p=0.059)$. Figure 4 shows the distribution of comorbidities and their combinations related to the rhinitis groups.

Table 2 shows the age of patients and onset age of rhinitis among each group of rhinitis patients according to the presence of each comorbidity. Non-sR and mono-sR patients with comorbid conjunctivitis or eczema were younger and showed an earlier onset of rhinitis than those
Fig. 3. Comorbidities among patients with non-sR, mono-sR, and poly-sR. Non-sR, non-sensitized rhinitis; mono-sR, monosensitized rhinitis; poly-sR, poly-sensitized rhinitis; DM, diabetes mellitus. ${ }^{*} p<0.0001$, ${ }^{* *} p=0.001,{ }^{* * *} p=0.006$.

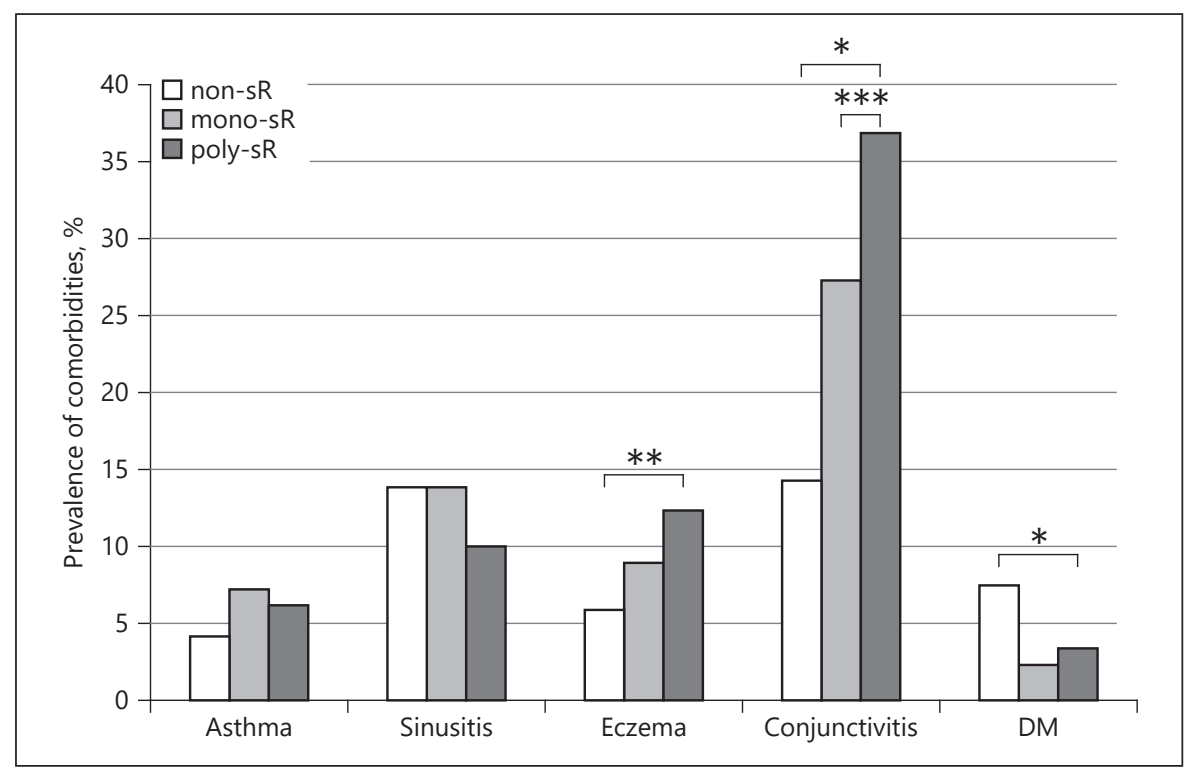


Table 2. Differences in age and age at onset of rhinitis according to allergic comorbidities

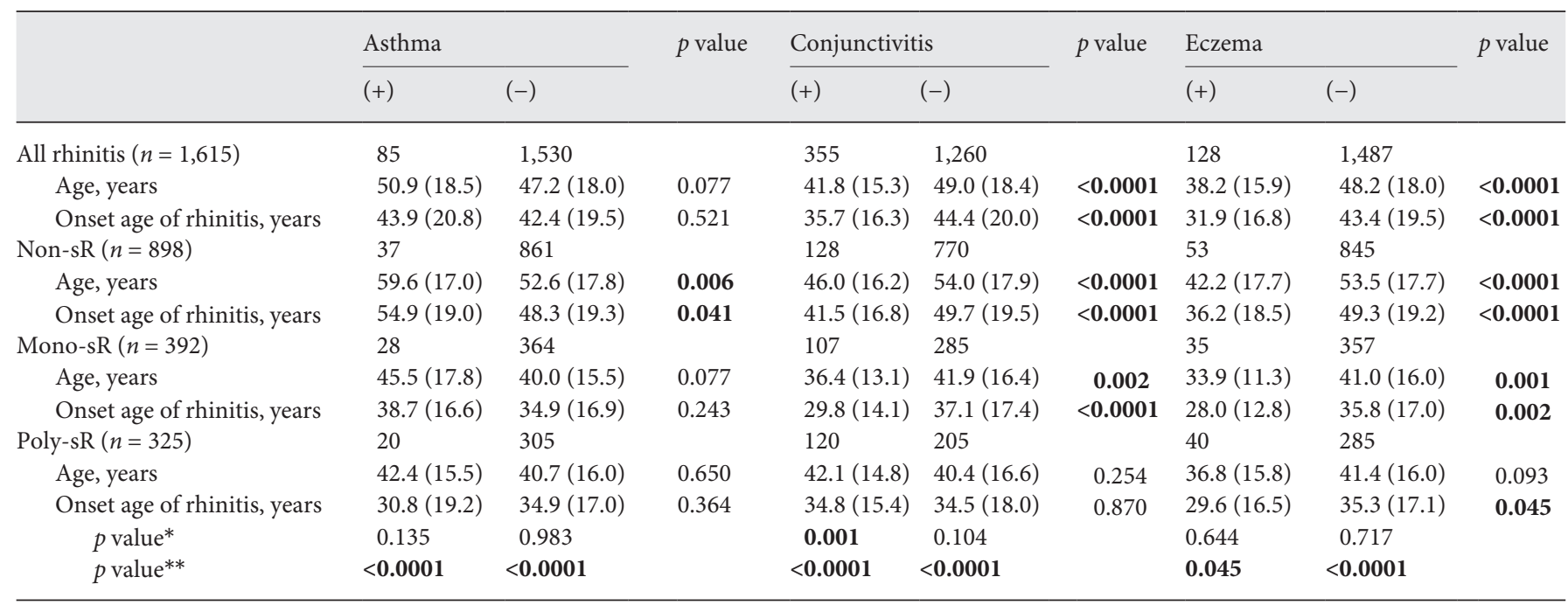

All ages and onset age of rhinitis are mean (SD). Non-sR, non-sensitized rhinitis; mono-sR, mono-sensitized rhinitis; poly-sR, poly-sensitized rhinitis; $(+)$, presence of the comorbidity; $(-)$, absence of the comorbidity. Bold typeface indicates $p<0.05 .{ }^{*}$ Onset age of rhinitis between patients with mono-sR and poly-sR. ** Onset age of rhinitis among patients with non-sR, mono-sR, and poly-sR.

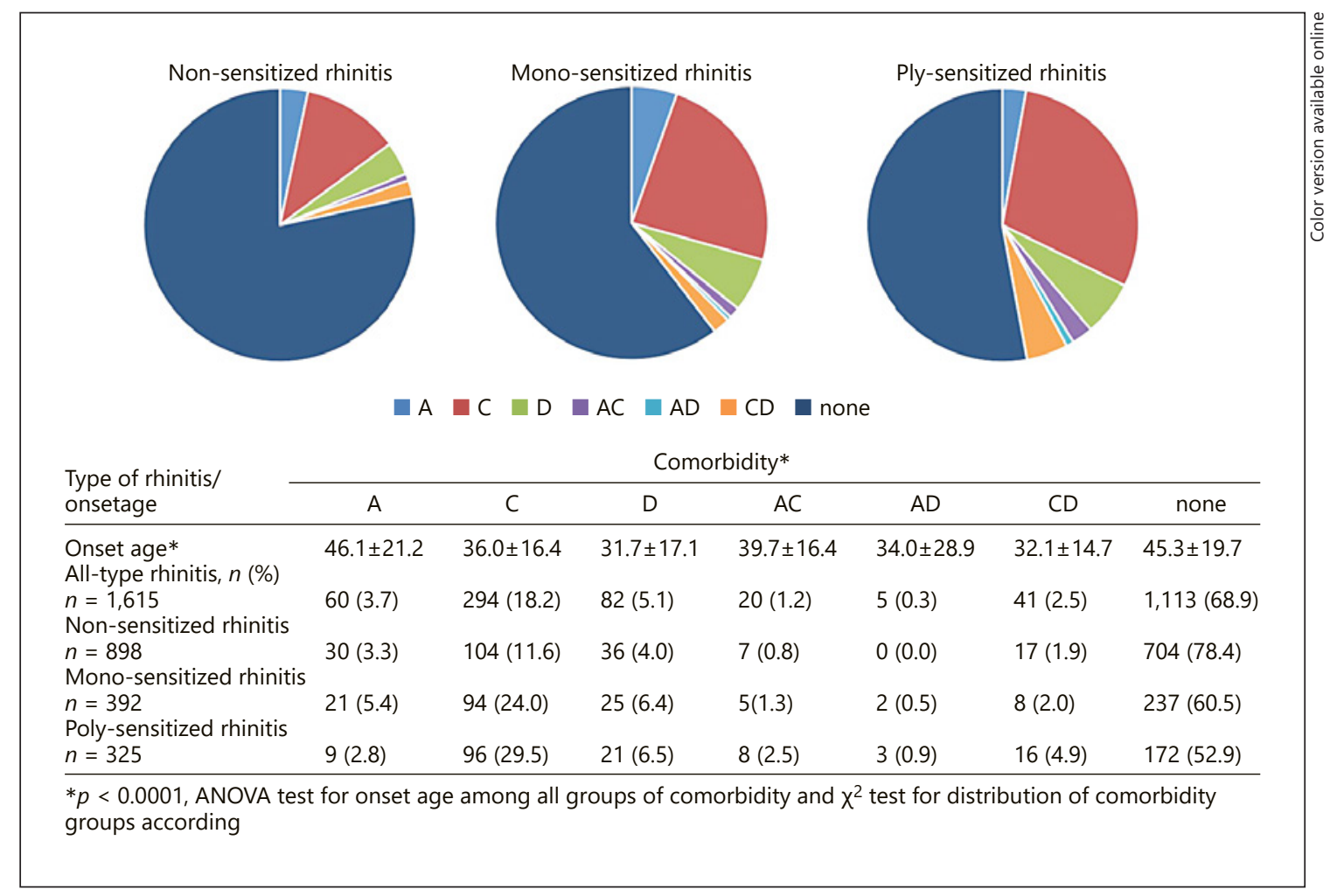

Fig. 4. Distribution of comorbidities and their combinations related with rhinitis groups. A, asthma; C, conjunctivitis; D, dermatitis; $\mathrm{AC}$, asthma and conjunctivitis; $\mathrm{AD}$, asthma and dermatitis; $\mathrm{CD}$, conjunctivitis and dermatitis. 
Table 3. Gender differences in comorbidity among patients within each rhinitis group

\begin{tabular}{|c|c|c|c|c|}
\hline Comorbidity & Rhinitis & Male & Female & $p$ value \\
\hline \multirow[t]{4}{*}{ Conjunctivitis } & Non-sR & $9.8 \%(47 / 482)$ & $19.5 \%(81 / 416)$ & $<0.0001$ \\
\hline & Mono-sR & $22.3 \%(49 / 220)$ & $33.7 \%(58 / 172)$ & 0.012 \\
\hline & Poly-sR & $31.1 \%(61 / 196)$ & $45.7 \%(59 / 129)$ & 0.008 \\
\hline & All rhinitis & $17.5 \%(157 / 898)$ & $27.6 \%(198 / 717)$ & $<0.0001$ \\
\hline \multirow[t]{4}{*}{ Eczema } & Non-sR & $4.4 \%(21 / 482)$ & $7.7 \%(32 / 416)$ & 0.034 \\
\hline & Mono-sR & $5.0 \%(11 / 220)$ & $14.0 \%(24 / 172)$ & 0.002 \\
\hline & Poly-sR & $9.7 \%(19 / 196)$ & $16.3 \%(21 / 129)$ & 0.077 \\
\hline & All rhinitis & $5.7 \%(51 / 898)$ & $10.7 \%(77 / 717)$ & $<0.0001$ \\
\hline \multirow[t]{4}{*}{ Asthma } & Non-sR & $4.4 \%(21 / 482)$ & $3.8 \%(16 / 416)$ & 0.097 \\
\hline & Mono-sR & $6.8 \%(15 / 220)$ & $7.6 \%(13 / 172)$ & 0.778 \\
\hline & Poly-sR & $6.1 \%(12 / 196)$ & $6.2 \%(8 / 129)$ & 0.977 \\
\hline & All rhinitis & $5.3 \%(48 / 898)$ & $5.2 \%(37 / 717)$ & 0.869 \\
\hline \multirow[t]{4}{*}{ Sinusitis } & Non-sR & $12.0 \%(58 / 482)$ & $15.9 \%(66 / 416)$ & 0.701 \\
\hline & Mono-sR & $10.9 \%(24 / 220)$ & $17.4 \%(30 / 172)$ & 0.063 \\
\hline & Poly-sR & $12.8 \%(25 / 196)$ & $5.4 \%(7 / 129)$ & 0.030 \\
\hline & All rhinitis & $11.9 \%(107 / 898)$ & $14.4 \%(103 / 717)$ & 0.146 \\
\hline \multirow[t]{4}{*}{$\mathrm{DM}$} & Non-sR & $9.5 \%(46 / 482)$ & $5.0 \%(21 / 416)$ & 0.011 \\
\hline & Mono-sR & $3.2 \%(7 / 220)$ & $1.2 \%(2 / 172)$ & 0.185 \\
\hline & Poly-sR & $5.1 \%(10 / 196)$ & $0.8 \%(1 / 129)$ & 0.035 \\
\hline & All rhinitis & $7.0 \%(63 / 898)$ & $3.3 \%(24 / 717)$ & 0.001 \\
\hline \multirow[t]{4}{*}{ Onset age of rhinitis, years } & Non-sR & $49.9 \pm 20.5$ & $46.6 \pm 17.8$ & 0.021 \\
\hline & Mono-sR & $34.6 \pm 18.0$ & $35.8 \pm 15.2$ & 0.462 \\
\hline & Poly-sR & $33.9 \pm 17.9$ & $35.7 \pm 15.7$ & 0.349 \\
\hline & All rhinitis & $42.7 \pm 20.9$ & $42.3 \pm 17.7$ & 0.669 \\
\hline
\end{tabular}

Non-sR, non-sensitized rhinitis; mono-sR, mono-sensitized rhinitis; poly-sR, poly-sensitized rhinitis; DM, diabetes mellitus. ${ }^{*} t$ test.

without these comorbidities. Non-sR patients with comorbid asthma were older and showed late onset of rhinitis, but this was not the case for patients with sensitized rhinitis. For comorbid conjunctivitis, the onset age of rhinitis was much younger in mono-sR patients with conjunctivitis than in poly-sR patients with conjunctivitis. Diabetes mellitus seemed to be more common in patients with non-sR than sensitized rhinitis, but it was not after adjustment for age of patients. Table 3 shows the gender difference for the prevalence of comorbidity according to the rhinitis groups. Conjunctivitis and eczema were more common in female patients in most of the rhinitis groups, but the onset age was not so different between male and female patients.

Figure 5 shows the sensitization profiles for $10 \mathrm{com}-$ mon inhalant allergens in patients with mono-sR and poly-sR. Since sensitization to pollen was more frequent in patients with poly-sR, we compared the clinical characteristics of mono-sR patients sensitized to HDM $(n=291)$ and sensitized to pollen $(n=64)$, including tree, ragweed, or mugwort, to which pollen more than 10 patients were sensitized, to evaluate the possible role of pollen allergens in the clinical differences between mono-sR and poly-sR (Table 4). There were no differences in the rhinitis symptoms and comorbidities of mono-sR patients sensitized to HDM and mono-sR patients sensitized to those pollens, although patients sensitized to pollen were older and reported a late onset of rhinitis.

For patients with poly-sR, the analysis for allergen groups (HDM, pollens, animal dander, cockroach, and molds) showed no differences in onset age and distribution of comorbidity among each allergen group. In addition, there were no differences in comorbidity and onset age according to the number of sensitized allergens based on the analysis of patients sensitized to 2-5 allergens (the number of patients sensitized to more than 5 allergens was too small; see online suppl. table; for all online suppl. material, see www.karger.com/doi/10.1159/000507444). 
Table 4. Comparison between patients with allergic rhinitis mono-sensitized to HDM and pollen

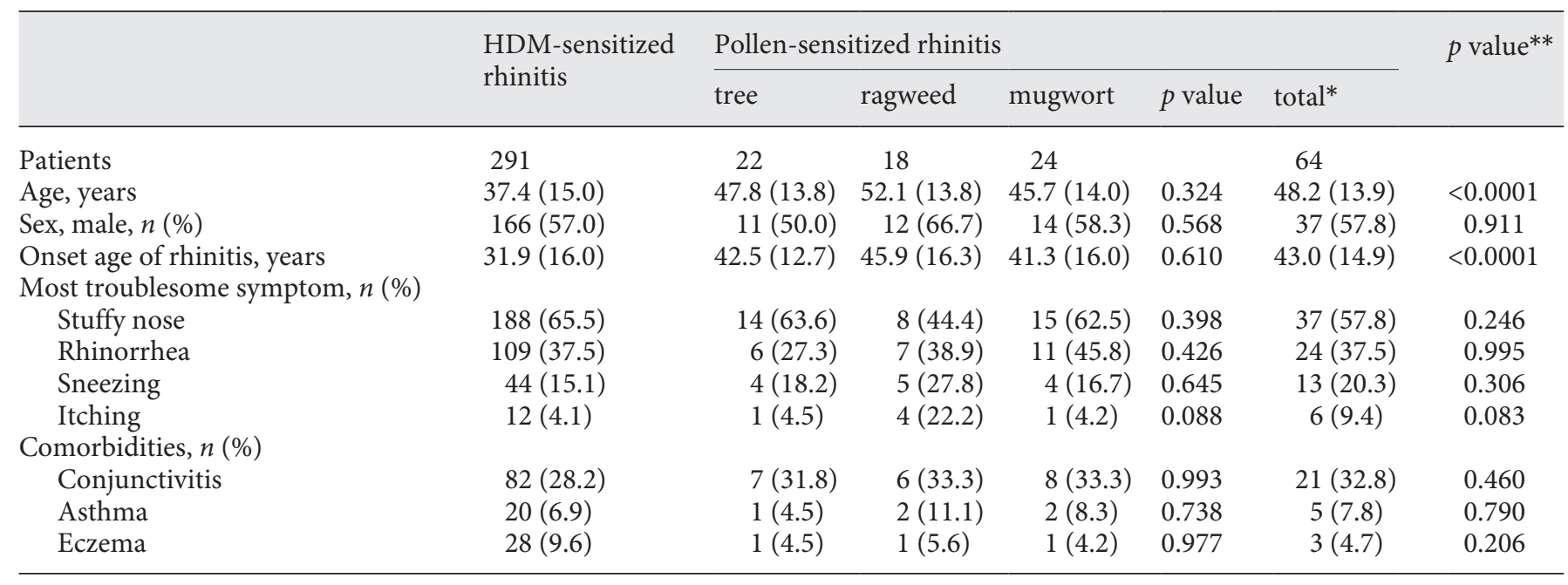

HDM, house dust mites. * All patients sensitized to any of the 3 pollen, tree, ragweed, and mugwort. ${ }^{* *}$ Comparison between HDMsensitized patients and all of the patients sensitized to any of the 3 pollen (total).

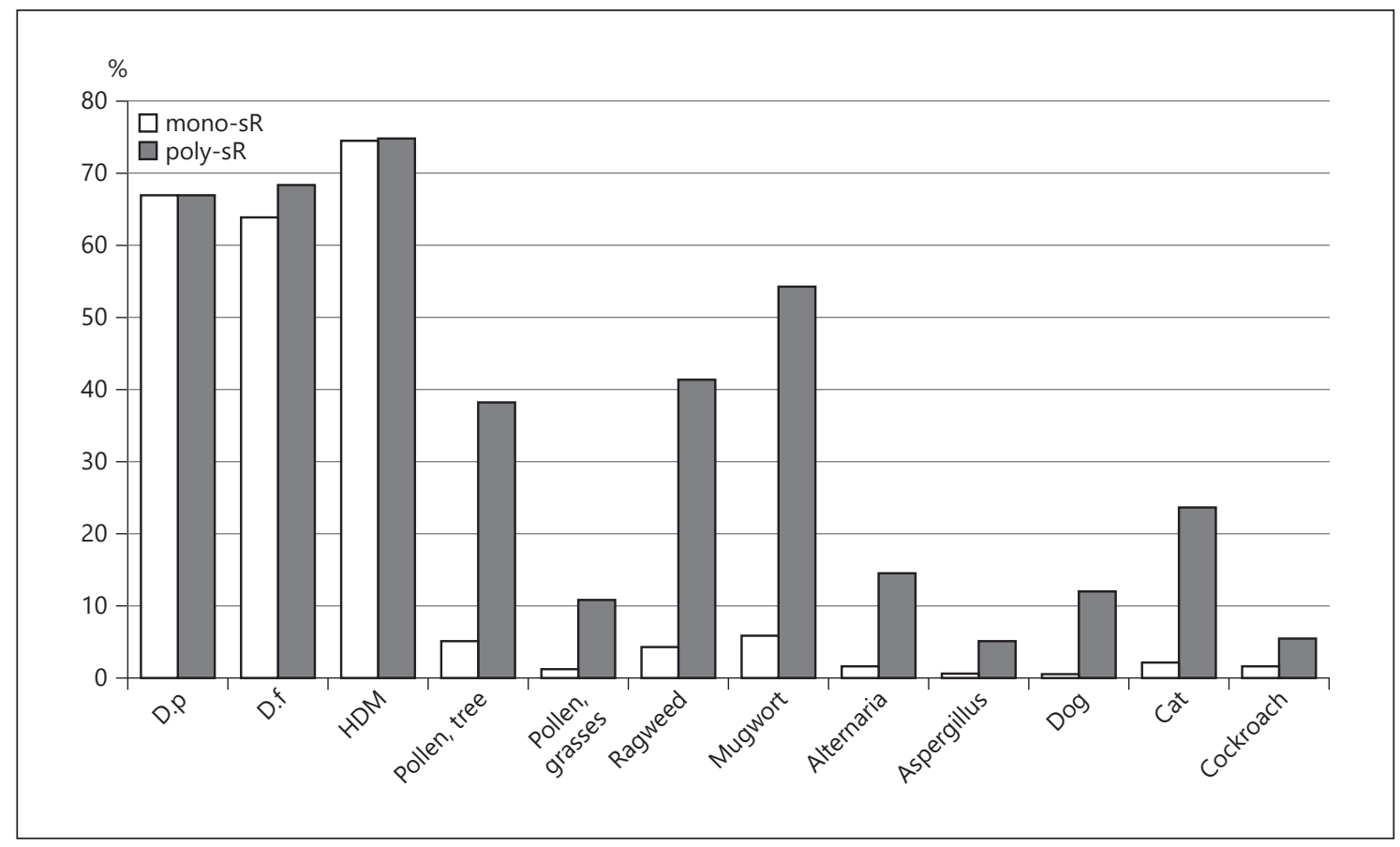

Fig. 5. IgE recognition frequencies based on skin prick tests according to mono-sensitized rhinitis and poly-sensitized rhinitis. IgE, immunoglobulin E; D.p, D. pteronyssinus; D.f, D. farinae; HDM, house dust mites; mono-sR, mono-sensitized rhinitis; poly-sR, poly-sensitized rhinitis. 


\section{Discussion}

Comorbid conjunctivitis and eczema were most common in poly-sR, followed by mono-sR; they were least common in non-sR. Nasal symptoms were more severe in patients with sensitized rhinitis, but there were no differences in severity of rhinitis symptoms between patients with mono-sR and poly-sR. Age at onset of rhinitis clearly differed between patients with non-sR and sensitized rhinitis, but not between those with mono-sR and poly-sR. However, the onset age of rhinitis seemed to differ depending on the presence of comorbid conjunctivitis and eczema among adult patients with non-sR and mono-sR.

It is consistent with the findings from the MeDALL project that prevalence of comorbid conjunctivitis is clearly related with the quantitative trait of IgE sensitization, and eczema showed a similar trend. The association between poly-sensitization and multimorbidity in adult patients with rhinitis in the current study seems to be inherent in the nature of poly-sensitization and not likely due to differences in sensitized allergens as observed in the comparison between mono-sR patients sensitized to HDM and to pollen. On the other hand, the association between asthma-rhinitis multimorbidity and IgE polysensitization is not clear in the current study, which is inconsistent with recent studies based on adult asthma cohorts that reported the asthma-rhinitis multimorbidity is associated with IgE poly-sensitization in adolescents and adults [19-21]. However, such a relationship between asthma-rhinitis multimorbidity and IgE poly-sensitization has not been consistent even in the European population [13, 22-24]. Non-sR showed a stronger association with asthma than allergic rhinitis in the European Community Respiratory Health Survey with 6,610 participants aged 20-44 years (odds ratio, 8.1 vs. 11.6) [13], and there have been reports that the relationship between asthma and IgE sensitization is not clear in adults and the elderly people $[23,24]$.

The findings in this study suggest that conjunctivitis and eczema showed a stronger relationship with polysensitization than did asthma in adult rhinitis patients. There could be tissue preferences in the mechanisms of poly-sensitization [6], which is related to the recent concept that the developmental origin may be related to higher changes of developing chronic inflammatory diseases $[25,26]$. In terms of the embryologic origin of these allergies, the nose, skin, and conjunctival epithelia are derived from the ectoderm, and the bronchus is derived from the endoderm [6]. Therefore, we suspect that the quantitative trait of IgE sensitization might preferentially involve organs derived from the ectoderm in adult patients with rhinitis. Actually, asthma in older patients was characterized as nonatopic or intrinsic for many years $[9,10]$.

Patients with non-sR were older and showed a later onset of rhinitis than sensitized rhinitis patients. Non-sR is a less well-defined condition and acts as an exclusion diagnosis. This has led to only a few studies on non-sR $[11,27]$, and its exact prevalence and phenotype are unknown. Nevertheless, there have been some studies which reported that non-sR is also associated with similar local IgE-induced inflammation in nasal mucosa, regardless of systemic atopy test findings which might be induced by an allergen or Staphylococcus aureus enterotoxin as a super-antigen [28-31]. However, the current study showed consistent results with a previous study, which is based on a cross-sectional study on 659 rhinitis patients aged 1444 years [11], that nasal symptoms of non-sR were milder than those for sensitized rhinitis. Several studies reported that patients with sensitized rhinitis have more sneezing and nasal pruritus, whereas patients with non-sR were characterized mainly by nasal obstruction and rhinorrhea $[11,12]$. The frequency and profiles of comorbidities also differed in patients with non-sR and sensitized rhinitis, and showed consistent results with a previous report, based on a cross-sectional study on 1,107 patients with rhinitis aged $>18$ years at single center, that patients with non-sR suffer more from sinusitis, whereas patients with sensitized rhinitis suffer more frequently from conjunctivitis [12].

The age at onset of rhinitis was clearly different between non-sR and sensitized rhinitis. Furthermore, the age at onset of rhinitis was different in each of non-sR and mono-sR patients according to the presence of comorbid conjunctivitis and eczema. These findings may suggest that rhinitis with multimorbidity might be different endotypes of rhinitis compared with rhinitis without such multimorbidity. The MeDALL study showed that monosensitization and poly-sensitization constitute 2 distinct phenotypes, whereas this study showed that mono-sR and poly-sR may be different even in terms of their multimorbidity such as conjunctivitis and eczema. For asth$\mathrm{ma}$, it is interesting that the presence of comorbid asthma in patients with rhinitis showed clearly different onset ages of rhinitis. It seems that there could be a distinct phenotype of non-sR that preferentially involves older people and is accompanied by asthma. Actually, most of the asthmatic patients have rhinitis, called the "one airway, one disease," but not all patients with rhinitis have asthma. 
Nonatopic asthma is more frequently observed among older patients with asthma $[9,10]$.

This study has several limitations. First, this study is not a population-based study. Since the patients were enrolled from those who visited the rhinitis clinic of the university hospital, there could be a selection bias, and it is possible that the severity of the rhinitis symptoms was biased toward moderate to severe, which means bothersome in daily life. So, this study may suggest heterogeneity of adult rhinitis with more than mild rhinitis symptoms according to IgE sensitization and comorbidity. Second, there could be concerns about whether a total of 10 inhaled allergens are enough to define non-sR, mono-sR, and poly-sR. Although a standard prick test panel for Europe for inhalants is proposed with 18 common inhalant allergens, modification of the number and panel of allergens is widely accepted for different regions [32]. Actually there have been many studies using similar profiles of allergens to define atopy [33] in Korea, and even several studies for the quantitative trait of IgE sensitization using a small number of allergens, such as 6 allergens for children [3] and 14 allergens for adults [34]. In the current study, ten common aeroallergens were selected based on cross-reactivity and frequency of sensitization in the community, and thus, this study may possibly represent the atopy status in Korea. Third, there could be potential classification bias such as nonallergic rhinitis with asymptomatic sensitization or possibly locally sensitized rhinitis. Since the relationship between rhinitis symptoms and exposure to sensitized allergens was not confirmed, we used non-sR and mono-/poly-sR instead of nonallergic rhinitis and mono-/poly-sensitized allergic rhinitis. Fourth, there may have been recall bias for most of the variables including the age at onset of rhinitis, but this bias would have been the same for all enrolled patients and each group regardless of the type of rhinitis. Finally, the season during which the patients were evaluated differed. However, as all patients were examined during their first visit to the rhinitis clinic, we assumed that most patients were evaluated when they were suffering from symptoms of rhinitis.
This study showed that the frequency of comorbid conjunctivitis and eczema in adult rhinitis patients differed by a quantitative trait of IgE sensitization. Furthermore, among each of the non-sR, mono-sR, and poly-sR patients, the onset age of rhinitis was different according to the presence of comorbidities, including conjunctivitis, eczema, and asthma, which might suggest distinct phenotypes or possibly different endotypes may present for such comorbidities.

\section{Acknowledgement}

This research was supported by the Bio \& Medical Technology Development Program of the National Research Foundation (NRF) funded by the Korean government (MSIT) (2019M3E5D3073365).

\section{Statement of Ethics}

This study protocol was approved by the Institutional Review Board of the hospital (Institutional Review Board number: KNUH2019-04-018).

\section{Disclosure Statement}

The authors have no conflicts of interest to declare.

\section{Funding Sources}

The authors did not receive any funding.

\section{Author Contributions}

Jae Won Jeong and Kyu-Hyoung Lim contributed to the study conduct and writing of the manuscript. Woo Hyun Lee and Jun Yeon Won contributed to the study conduct. Jae Won Jeong and Jae-Woo Kwon did the statistical analysis.

\section{References}

1 Eder W, Ege MJ, von Mutius E. The asthma epidemic. N Engl J Med. 2006;355(21):222635.

2 Spergel JM, Paller AS. Atopic dermatitis and the atopic march. J Allergy Clin Immunol. 2003;112(6):S118-27.

3 Pinart M, Benet M, Annesi-Maesano I, von Berg A, Berdel D, Carlsen KC, et al. Comorbidity of eczema, rhinitis, and asthma in ige- sensitised and non-ige-sensitised children in medall: a population-based cohort study. Lancet Respir Med. 2014;2(2):131-40.

4 Bousquet J, Anto J, Auffray C, Akdis M, Cambon-Thomsen A, Keil T, et al. Medall (mechanisms of the development of allergy): an integrated approach from phenotypes to systems medicine. Allergy. 2011;66(5):596604. 
5 Antó JM, Pinart M, Akdis M, Auffray C, Bachert C, Basagaña X, et al. Understanding the complexity of ige-related phenotypes from childhood to young adulthood: a mechanisms of the development of allergy (medall) seminar. J Allergy Clin Immunol. 2012; 129(4):943-e4.

6 Bousquet J, Anto JM, Wickman M, Keil T, Valenta R, Haahtela T, et al. Are allergic multimorbidities and ige polysensitization associated with the persistence or re-occurrence of foetal type 2 signalling? The medall hypothesis. Allergy. 2015;70(9):1062-78.

7 Anto JM, Bousquet J, Akdis M, Auffray C, Keil T, Momas I, et al. Mechanisms of the development of allergy (medall): introducing novel concepts in allergy phenotypes. J Allergy Clin Immunol. 2017;139(2):388-99.

8 Just J, Deslandes-Boutmy E, Amat F, Desseaux K, Nemni A, Bourrat E, et al. Natural history of allergic sensitization in infants with early-onset atopic dermatitis: results from orca study. Pediatr Allergy Immunol. 2014; 25(7):668-73.

9 Yáñez A, Cho SH, Soriano JB, Rosenwasser LJ, Rodrigo GJ, Rabe KF, et al. Asthma in the elderly: what we know and what we have yet to know. World Allergy Organ J. 2014;7(1):8.

10 Reed CE. The natural history of asthma. J Allergy Clin Immunol. 2006;118(3):543-8.

11 Mølgaard E, Thomsen SF, Lund T, Pedersen L, Nolte H, Backer V. Differences between allergic and nonallergic rhinitis in a large sample of adolescents and adults. Allergy. 2007; 62(9):1033-7.

12 Di Lorenzo G, Pacor ML, Amodio E, LetoBarone MS, La Piana S, D'Alcamo A, et al. Differences and similarities between allergic and nonallergic rhinitis in a large sample of adult patients with rhinitis symptoms. Int Arch $\mathrm{Al}$ lergy Immunol. 2011;155(3):263-70.

13 Leynaert B, Bousquet J, Neukirch C, Liard R, Neukirch F. Perennial rhinitis: an independent risk factor for asthma in nonatopic subjects: results from the european community respiratory health survey. J Allergy Clin Immunol. 1999;104(2 Pt 1):301-4.
14 Zhang N, Van Zele T, Perez-Novo C, Van Bruaene N, Holtappels G, DeRuyck N, et al. Different types of $\mathrm{t}$-effector cells orchestrate mucosal inflammation in chronic sinus disease. J Allergy Clin Immunol. 2008;122(5): 961-8.

15 Song WJ, Kim MY, Jo EJ, Kim MH, Kim TH, $\mathrm{Kim} \mathrm{SH}$, et al. Rhinitis in a community elderly population: relationships with age, atopy, and asthma. Ann Allergy Asthma Immunol. 2013;111(5):347-51.

16 Heinzerling L, Frew AJ, Bindslev-Jensen C, Bonini S, Bousquet J, Bresciani M, et al. Standard skin prick testing and sensitization to inhalant allergens across europe: a survey from the galen network. Allergy. 2005;60(10): 1287-300.

17 van der Valk JP, Gerth van Wijk R, Hoorn E, Groenendijk L, Groenendijk IM, de Jong NW Measurement and interpretation of skin prick test results. Clin Transl Allergy. 2015;6:8.

18 Dreborg S. Allergen skin prick test should be adjusted by the histamine reactivity. Int Arch Allergy Immunol. 2015;166(1):77-80.

19 Siroux V, Ballardini N, Soler M, Lupinek C, Boudier A, Pin I, et al. The asthma-rhinitis multimorbidity is associated with ige polysensitization in adolescents and adults. Allergy. 2018;73(7):1447-58.

20 Burte E, Bousquet J, Varraso R, Gormand F, Just J, Matran R, et al. Characterization of rhinitis according to the asthma status in adults using an unsupervised approach in the egea study. PloS One. 2015;10(8):e0136191.

21 Raciborski F, Bousquet J, Bousqet J, Namysłowski A, Krzych-Fałta E, Tomaszews$\mathrm{ka} \mathrm{A}$, et al. Dissociating polysensitization and multimorbidity in children and adults from a polish general population cohort. Clin Transl Allergy. 2019;9:4.

22 Shaaban R, Zureik M, Soussan D, Neukirch C, Heinrich J, Sunyer J, et al. Rhinitis and onset of asthma: a longitudinal population-based study. Lancet. 2008;372(9643):1049-57.

23 Anto JM. The causes of asthma: the need to look at the data with different eyes. Allergy. 2004;59(2):121-3.

24 Pearce N, Douwes J, Beasley R. Is allergen exposure the major primary cause of asthma? Thorax. 2000;55(5):424-31.
25 Haugen AC, Schug TT, Collman G, Heindel JJ. Evolution of dohad: the impact of environmental health sciences. J Dev Orig Health Dis. 2015;6(2):55-64

26 Bousquet J, Anto JM, Berkouk K, Gergen P, Antunes JP, Augé P, et al. Developmental determinants in non-communicable chronic diseases and ageing. Thorax. 2015;70(6): 595-7.

27 Bachert C, van Cauwenberge P, Olbrecht J, van Schoor J. Prevalence, classification and perception of allergic and nonallergic rhinitis in belgium. Allergy. 2006;61(6):693-8.

28 Rondón C, Romero JJ, López S, Antúnez C, Martín-Casañez E, Torres MJ, et al. Local ige production and positive nasal provocation test in patients with persistent nonallergic rhinitis. J Allergy Clin Immunol. 2007;119(4): 899-905.

29 Gevaert P, Holtappels G, Johansson SG, Cuvelier C, Cauwenberge P, Bachert C. Organization of secondary lymphoid tissue and local ige formation to staphylococcus aureus enterotoxins in nasal polyp tissue. Allergy. 2005;60(1):71-9.

30 Bachert C, Zhang N, Patou J, van Zele T, Gevaert $\mathrm{P}$. Role of staphylococcal superantigens in upper airway disease. Curr Opin Allergy Clin Immunol. 2008;8(1):34-8.

31 Van Zele T, Gevaert P, Watelet JB, Claeys G, Holtappels G, Claeys C, et al. Staphylococcus aureus colonization and ige antibody formation to enterotoxins is increased in nasal polyposis. J Allergy Clin Immunol. 2004;114(4): 981-3.

32 Heinzerling L, Mari A, Bergmann KC, Bresciani M, Burbach G, Darsow U, et al. The skin prick test: european standards. Clin Transl Allergy. 2013;3(1):3.

33 Jang AS, Kim SH, Kim TB, Park HW, Kim SH, Chang YS, et al. Impact of atopy on asthma and allergic rhinitis in the cohort for reality and evolution of adult asthma in korea. Allergy Asthma Immunol Res. 2013;5(3):143-9.

34 Ciprandi G, Cirillo I. Monosensitization and polysensitization in allergic rhinitis. Eur J Intern Med. 2011;22(6):e75-9. 